\title{
Sıcaklı̆ı̆n Puccinia menthae Ürediosporlarının Çimlenmesi Üzerine Etkisi
}

\section{Birsen GEÇIOĞLU ERINCIK ${ }^{* 1}$ (I)}

\author{
${ }^{1}$ Aydın Adnan Menderes Üniversitesi, Koçarlı Meslek Yüksekokulu, Aydın
}

Öz: Puccinia menthae'nin neden olduğu pas hastalığı nane yetiştiriciliğinde verimi ve nane yağı kalitesini olumsuz etkileyen faktörlerin başında gelmektedir. Hastalıklı bitkilerde yaprakların üst kısmında açık sarı lekeler, yaprakların altında ve gövdede turuncu-kahverengi veya siyah püstüller oluşmaktadır. Hastalığın çok şiddetli olduğu bitkilerde yaprak dökülmeleri yaygın olarak görülmektedir. Aydın ilinde yapılan gözlemlerde nane pası hastalık şiddetinin sezon içerisinde önemli bir değişim gösterdiği belirlenmiş ve bunda Aydın ili iklim koşullarının önemli olabileceği düşünülmüştür. Ancak hastalığın gelişiminde çevresel faktörlerin etkisini ortaya koyan sınırlı sayıda çalışma bulunmaktadır. Bu çalışma; Aydın ilinde nane pası hastalığının sezon döneminde gelişiminin daha iyi anlaşılabilmesi için sıcaklığın P. menthae ürediosporlarının çim tüpü gelişimi üzerine etkisinin belirlenmesi amacıyla ele alınmıştır. Bunun için, doğal olarak enfekte olmuş bitkilerden elde edilmiş ürediosporlar su agar ortamı ile kaplı lam üzerinde farklı sıcaklıklarda çimlenmeleri yönünden gözlemlenmişlerdir. Her bir inokule edilmiş lam steril petri kabı içerisine yerleştirildikten sonra karanlıkta 5, 10, 15, 20, 25, 30 ve $35^{\circ} \mathrm{C}$ sıcaklık koşullarına ayarlanmış inkübatörlerde 16 saat süre ile inkübasyona bırakılmıştır. Inkübasyon sonunda her bir lamelde çimlenen 45 ürediosporun çim tüpü uzunluğu bir bilgisayar programı aracılığıyla ölçülmüştür. Inkübasyon süresinin sonunda 5, 30 ve $35{ }^{\circ} \mathrm{C}$ sıcaklıklarda çimlenme olmaz iken, $10,15,20,25^{\circ} \mathrm{C}$ sıcaklıklarda hemen hemen tüm ürediosporlar çimlenmiştir. En uzun çim tüpü oluşumu ortalama $661.8 \mu \mathrm{m}$ ile $20^{\circ} \mathrm{C}^{\prime}$ de gözlenmiştir. Ortalama çim tüp uzunluğu $15^{\circ} \mathrm{C}^{\prime} \mathrm{de} 602,5 \mu \mathrm{m}, 10^{\circ} \mathrm{C}^{\prime} \mathrm{de}$ $489,3 \mu \mathrm{m}, 25^{\circ} \mathrm{C}^{\prime}$ de 245,5 $\mu \mathrm{m}^{\prime}$ dir. Sonuç olarak; bu çalışmada elde edilen bulgular, P. menthae' nin sporlarının serin koşullarda daha iyi çimlenen bir patojen olduğunu göstermektedir.

Anahtar kelimeler: Pas, yaprak, nane, çim tüpü

\section{Effect of Temperature on Urediospores Germination of Puccinia menthae}

\begin{abstract}
Rust disease, caused by Puccinia menthae, is one of the main factors that reduces the yield of peppermint and affects the overall quality of peppermint oils. On the infected plants, light yellow spots on the upper surface of the leaves and orange-brown or dark pustules the under side of the leaves and on the stems are formed. Falling out of leaves on the severly infected plants is very common. During the observations conducted in Aydin Province, it was determined that the severity of the disease has changed significantly throughout the growing season and it was considered that the climatic conditions of Aydin province may be the effect on this. There are limited number of studies demonstrating the effect of climatic factors in the development of the disease. For better understanding of the seasonal development of peppermint rust in Aydin province, this study aimed to determine the effect of temperature on the germ tube development from $P$. menthae urediospores. For this purpose, urediospores collected from naturally infected plants were tested on water agar layeredglass slides for germination and germ tube development under different temperature conditions. After each inoculated slide was placed in a sterile petri dish, it was placed to incubate for 16 hours in incubators adjusted to 5, 10,15, 20, 25, 30 and $35^{\circ} \mathrm{C}$ temperature conditions in the dark. At the end of incubation, germ tube length of 45 urediospores germinated in each glass slide was measured by using a computer software. At the end of the incubation period, no germination was observed at 5,30 and $35^{\circ} \mathrm{C}$, while almost all spores germinated at the temperature of $10,15,20,25^{\circ} \mathrm{C}$. The longest germ tube formation was observed at $20^{\circ} \mathrm{C}$ with an average of $661.8 \mu \mathrm{m}$. Average of the germ tube length was $602.5 \mu \mathrm{m}$ at $15^{\circ} \mathrm{C}, 489.3 \mu \mathrm{m}$ at $10^{\circ} \mathrm{C}$ and $245.5 \mu \mathrm{m}$ at $25^{\circ} \mathrm{C}$. When all data were analysed according to regression analysis, the optimum temperature for germination of urediospore was determined as $18.13^{\circ} \mathrm{C}$. As a result, the findings obtained in this study indicated that $P$. menthae is a pathogen that grows better in cool weather.
\end{abstract}

Keywords: Rust, leaf, peppermint, germ tube

\section{GiRiş}

Nane, Lamiaceae familyasına ait çok yıllık aromatik bir bitki olup dünyanın birçok ülkesinde gıda, ilaç, kozmetik ve parfümeri sanayisinde yaygın olarak kullanılmaktadır. (Özgüven ve Kırıcı,1999). Anavatanının, Orta Avrupa ve Asya olduğu belirtilen nane, dünyada geniş bir yayılış alanına sahiptir. Çoğunlukla Avrupa ve Asya'da yayılan 90 kadar türü bulunmaktadır. Bunlar arasında tarımı tapılan başlıca türler; Mentha arvensis, M. pulegium, M. aguatica, M. piperita, M. longifolia, M. suaveolens, M. spicata'dır (Gobert ve ark., 2002; Tucker ve Naczi, 2007). Nane yetiştiriciliğinin önemli sebeplerinden biri olan nane yağı, aromatik yağ olarak dünyada narenciye yağından sonra ikinci sırada gelmektedir (Özgüven ve Kırıcı,1999). Birleşmiş Milletler Gıda ve Tarım Örgütü'ne göre dünyada yıllık 30 bin tonun üzerinde nane üretimi yapılmaktadır. Ekonomik

*Sorumlu Yazar: bgerincik@adu.edu.tr. Bu çalışma 4. Uluslararası Mardin Artuklu Bilimsel Araştırmalar Kongresinde Sunulmuştur ve özeti bildiri kitapçı̆ı̆nda yayınlanmıştır.

Geliş Tarihi: 19 Mart 2021

Kabul Tarihi: 8 Haziran 2021 
değeri yüksek tarımsal bir ürün olmasının yanı sıra nane, hobi bahçeciliğinde saksı ve dış mekan (arka bahçe) bitkisi olarak da sıklıkla tercih edilmektedir ( Anonim, 2018).

Puccinia menthae Pers.'in neden olduğu pas hastalığı nane yetiştiriciliğini olumsuz etkileyen faktörlerin başında gelmektedir (Harvey, 1979; Edwards ve ark., 1998). Başta yapraklar olmak üzere yeşil aksamı enfekte eden etmen, oluşturduğu lezyonlar ile nane bitkilerinde gelişimi olumsuz etkilerken ürünün görüntü, aromatik yağ ve besin içeriği gibi kaliteye yönelik özelliklerinin azalmasına da sebep olmaktadır. Etkilenen bitkilerin karakteristik belirtisi olarak yaprakların üst kısmında açık sarı lekeler görülürken, yaprakların altında ve genç sürgünlerde turuncu-kahverengi püstüller oluşmaktadır. Sezon içerisinde leke sayısı yoğun bir şekilde artarak yaprağın tüm yüzeyini kaplayacak hale gelebilmektedir. Hastalığın şiddetli olarak ortaya çıktığı durumlarda, pas belirtilerinin daha fazla görüldüğü alt ve orta yapraklar dökülmekte ve bitkide sadece tepe yapraklar kalmaktadır (Meyer ve ark., 2010).

$P$. menthae, birçok pas fungusu gibi, konukçu üzerinde sırayla oluşan beş farklı spor (basidiospor, spermati, aeciospor, ürediospor, teliospor) dönemlerini içeren karmaşık bir yaşam döngüsüne sahip monoik bir pas fungusudur (Horner, 1954). Bu sporlardan basidiospor, aeciospor ve ürediospor konukçuda belli dönemlerde enfeksiyonlara sebep olmaktadır. Basidiosporlar ve aeciosporlar sezon içerisinde bir kez enfeksiyondan sorumlu olurken, ürediosporlar çevre ve konukçu koşulları uygun olduğu durumlarda sezon boyunca tekrarlayan döngüler halinde çok sayıda enfeksiyon meydana getirirler. Rüzgar ile taşınarak uzak mesafelere dağılma özelliğine sahip bu sporlar, sezon boyunca hastalık yaygınlığının ve şiddetinin artmasından sorumlu olmaktadırlar (Beresford ve Mulholland, 1987). Bitkilerde leke sayısının yaprak yüzeyinin tamamını kaplayabilecek şekilde artması ve yoğun yaprak dökümleri ürediospor enfeksiyonları sırasında meydana gelmektedir (Meyer ve ark., 2010).

Nane pası ile mücadelede çoğunlukla kültürel önlemler ve dayanıklı çeşit kullanımı ön plana çıksa da bunların yeterli olmadığı durumlarda fungisit kullanımına başvurulabilmektedir (Edwards ve ark., 1999). Fungisit uygulamaları ile hastalığın şiddetli hale gelmesinde sorumlu olan ürediospor kaynaklı enfeksiyonlar hedef alınarak hastalık şiddeti engellenebilmektedir. Ancak yoğun fungisit kullanımı, özellikle nanenin taze olarak tüketimi söz konusu ise, insan sağlığına zararlı olan kalıntı sorununa yol açabilecek olması sebebiyle sakıncalı bir durumdur. Kimyasal mücadelede başarı, kullanılan fungisitin etki mekanizmasının yanı sıra fungisit uygulama zamanına göre de değişebilmektedir. Bitki hastalıklarında çeşitli çevresel faktörlere bağlı olarak enfeksiyonların etkinliği azalmakta veya artmaktadır (Edwards, 1999). Enfeksiyon etkinliğinin az olduğu çevre koşullarında gereksiz olabilecek fungisit uygulamalarından kaçınmak nanede pestisit kalıntı probleminin azalmasını ve daha etkin bir kontrolün yapılmasını sağlayabilir. Ancak nane pası hastalığının gelişmesine etki eden çevresel faktörler üzerine sınırlı sayıda çalışma bulunmaktadır. Sıcaklık faktörü bunlardan en çok çalışılanı olmuş ve elde edilen sonuçlara göre sıcaklığın $P$. menthae üzerine etkisi izolata ve ülkeye göre farklılıklar göstermiştir. 1945 yılında ABD'de yayınlanan çalışmada $P$. menthae ürediosporlarının $9-27^{\circ} \mathrm{C}$ arasında çimlendiği ve $18{ }^{\circ} \mathrm{C}^{\prime}$ de en ideal çimlenme ve gelişme gösterdiği bildirilmiştir (Neiderhauser, 1945). Ancak yine ABD'de yapılan başka bir çalışmada ise farklı nane türlerinden elde edilen izolatların sıcaklık koşullarına farklı tepkiler verdikleri belirtilmiştir (Johnson ve Cummings, 2013). Avustralya'da yapılan bir çalışmada da $P$. menthae sporlarının 5 ile $30{ }^{\circ} \mathrm{C}$ dereceleri arasında çimlendiği ve en iyi çimlenmenin $20{ }^{\circ} \mathrm{C}$ 'de meydana geldiği bildirilmiştir (Edwards ve ark., 1998). Ülkemiz koşullarında yerel nanelerde pasa sebep olan $P$. menthae' nın sıcaklık istekleri üzerine henüz bir çalışma yapılmamıştır. Bu çalışma; in vitro'da farklı sıcaklık koşullarının nane pası hastalığı etmeni $P$. menthae ürediosporlarının çim tüpü gelişimi üzerine etkisini belirlemek amacıyla gerçekleştirilmiştir.

\section{MATERYAL VE YÖNTEM}

\section{Ürediosporların Elde Edilmesi}

Sıcaklık denemelerinde kullanılmak amacıyla, Aydın ilinde bir nane üretim alanından nane pası belirtileri gösteren bitkilerden yaprak örnekleri toplanmıştır. Alınan örneklerde $P$. menthae ürediosporlarının varlığı mikroskobik inceleme ile teyit edilmiştir. Ürediosporlu yaprak örnekleri üzerinde bulunan üredium püstüllerine steril kıl fırça ile sürtülerek ürediosporlar steril bir kurutma kağıdı üzerinde toplanmıştır. Daha sonra ürediosporlar içerisinde steril su bulunan tüplere transfer edilerek spor süspansiyonu elde edilmiştir. Elde edilen süspansiyonda spor sayımı hemasitometre ile yapılmış ve seyreltme işlemi ile konsantrasyonu $1 \times 10^{3}$ ürediospor/ml olacak şekilde ayarlanmıştır.

\section{Sıcaklığın Çim Tüpü Gelişimine Etkisi}

Ürediosporların çimlenme ve çim tüpü gelişimini mikroskop altında ölçme imkanı verecek bir tarafı su agar ile kaplı lamdan oluşan besi ortamı kullanılmıştır. Bu amaçla $2.5 \times 8$ cm boyutlarında mikroskop lamları ilk olarak kuru sıcaklıkta steril edilmiştir. Her bir steril lam $9 \mathrm{~cm}$ çapı olan bir steril petri kabına yerleştirilmiştir. Ardından lamın üst yüzeyine eriyik halde bulunan \%2'lik su agar ortamından $2 \mathrm{ml}$ damlatılmıştır. Bir baget yardımı ile su agarı lamın üzerine homojen bir şekilde yayılmış ve katılaşmaya bırakılmıştır. 
Daha önce hazırlanmış spor süspansiyondan $500 \mu \mathrm{l}$ alınarak üzerinde katı su agarı bulunan lam yüzeyine damlatılmış ve bir baget yardımı ile süspansiyonun ortam üzerine homojen olarak dağılması sağlanmıştır. Lamlar petri kapları içerisinde $5,10,15,20,25,30$ ve $35^{\circ} \mathrm{C}$ sıcaklık koşullarında 16 saat süre ile inkübasyona bırakılmıştır. Deneme beş tekerrürlü olarak tesadüf parselleri deneme desenine göre kurulmuş ve iki farklı zamanda tekrar edilmiştir. İnkübasyonun hemen sonrasında tüm lamlara \%95'lik acid fuchsin damlatılmış ve tüm petriler ölçüm yapılıncaya kadar $5{ }^{\circ} \mathrm{C}$ 'de bekletilmiştir. Her bir lam üzerinde çimlenen 45 ürediosporun çim tüpü uzunluğu «Olympus labSens» bilgisayar programı kullanılarak ölçülmüştür.

\section{İstatiksel Analiz}

Her bir tekerrür için ölçülen 45 sporun çim tüpü uzunluğunun ortalaması alınarak istatiksel analizde bu değerler kullanılmıştır. illk olarak çok yönlü ANOVA ile iki deneme tekrarı arasında istatiksel bir farkın olup olmadığına bakılmıştır. Aralarında fark olmaması sebebiyle 2 deneme tekrarının verileri birleştirilerek regresyon analizi yapılmıştır. Regresyon analizinde veriye en iyi uyum sağlayan model seçilmiştir. Optimum Gelişme Sıcaklık hesaplamasında regresyon analizinde en iyi model olan quadratic model $\left(\mathrm{y}=a \mathrm{x}^{2}+b \mathrm{x}+c\right)$ parametreleri kullanılmıştır. Buna göre; Optimum Gelişme Sıcaklığı $\left({ }^{\circ} \mathrm{C}\right)=b / 2 a$ formülü üzerinden hesaplanmıştır.

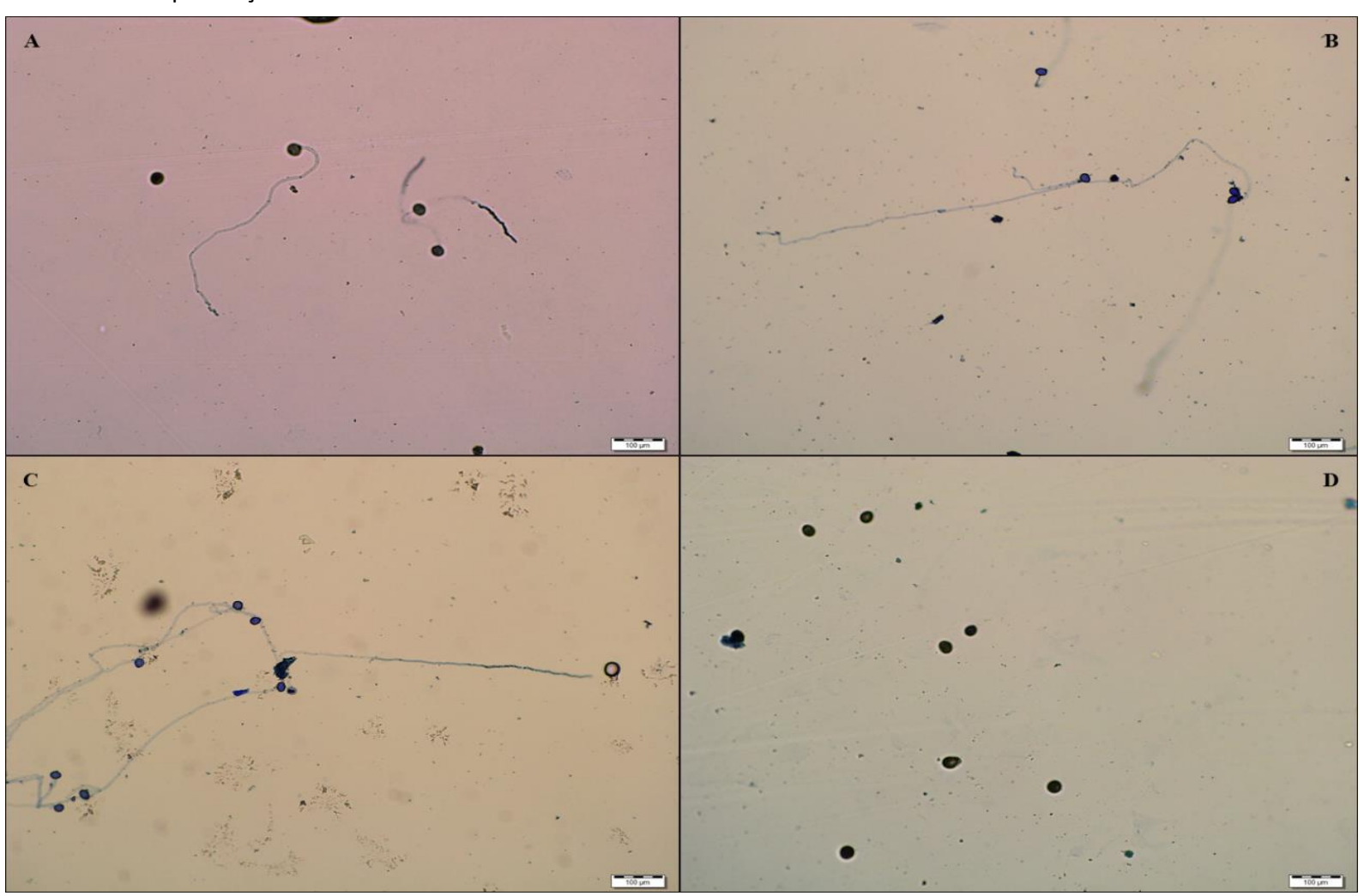

Şekil 1. 16 saat inkubasyon sonunda $10^{\circ} \mathrm{C}(\mathrm{A}), 15^{\circ} \mathrm{C}(\mathrm{B}), 20^{\circ} \mathrm{C}(\mathrm{C}), 30^{\circ} \mathrm{C}(\mathrm{D})$ sıcaklıkta Puccinia menthae'nin ürediosporlarında çim tüpü oluşumu

\section{BULGULAR VE TARTIŞMA}

Her iki denemede de 16 saat süren inkübasyon süresi sonunda 5,30 ve $35^{\circ} \mathrm{C}^{\prime}$ de ürediospor çimlenmesi olmamıştır. Birinci deneme ve ikinci deneme arasında istatistiki olarak önemli bir fark olmaması nedeniyle iki denemenin verileri birleştirilmiştir. En uzun çim tüpü oluşumu Çizelge 1 ve Şekil $1^{\prime}$ de de görüldüğü üzere ortalama $661.75 \mu \mathrm{m}$ ile $20^{\circ} \mathrm{C}^{\prime}$ de gözlemlenmiştir. Çim tüpü uzunluğu $15^{\circ} \mathrm{C}^{\prime}$ de $602.42 \mu \mathrm{m}, \quad 10^{\circ} \mathrm{C}^{\prime}$ de $490.93 \mu \mathrm{m}$ ve 25 ${ }^{\circ} \mathrm{C}^{\prime}$ de $245.54 \mu \mathrm{m}$ olmuştur. Bu sonuçlara göre etmenin dar bir sıcaklık aralığında geliştiği görülmektedir (Çizelge 1).

Çizelge 1. Farklı sıcaklık koşullarında 16 saat inkübasyon sonunda Puccinia menthae'nin ürediosporlarında çim tüpü uzunluğu

\begin{tabular}{lccc}
\hline Sıcaklık $\left({ }^{\circ} \mathbf{C}\right)$ & \multicolumn{3}{c}{ Çim tüpü uzunluğu $(\boldsymbol{\mu m})$} \\
\cline { 2 - 4 } & I. Deneme & II. Deneme & Ortalama \\
\hline 5 & 0.0 & 0.0 & 0.0 \\
10 & 497.50 & 484.36 & 490.93 \\
15 & 612.72 & 592.11 & 602.42 \\
20 & 673.76 & 649.74 & 661.75 \\
25 & 266.53 & 224.56 & 245.54 \\
30 & 0.0 & 0.0 & 0.0 \\
35 & 0.0 & 0.0 & 0.0 \\
\hline
\end{tabular}

GEÇioĞLU ERINCiK B 
Tüm veriler regresyon analizine göre değerlendirildiğinde regresyon eğrisinin sola daha fazla yatık olduğu görülmektedir. Buradan serin havaların etmen için daha uygun koşullar olduğu söylenebilir. Eğrinin en iyi ifade edildiği regresyon modeli quadratic model olmuştur. Quadratic model:

$$
Y=-265.9+89.36 X-2.472 X^{2}
$$

Formülde; $Y$, çim tüpü uzunluğunu ve $X$, sıcaklığı ifade etmektedir. $\mathrm{R}^{2}$ değeri ile modelin geçerliliği \% 72.5 olarak bulunmuştur (Şekil 2). Sözü edilen parametreler kullanılarak yapılan hesaplamalarda $P$. menthae ürediosporlarının çimlenmesi için optimum sıcaklık $18.13{ }^{\circ} \mathrm{C}$ olarak belirlenmiştir.

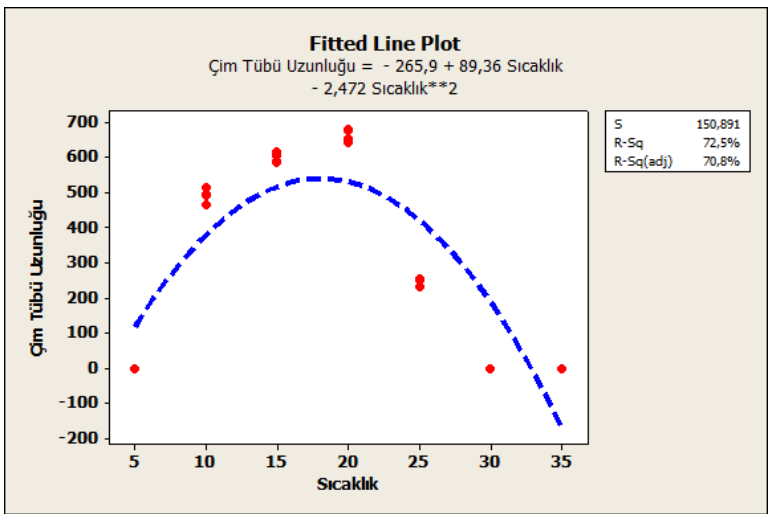

Şekil 2. Puccinia menthae'nin ürediosporlarının sıcaklık ve çim tüpü uzunluğu arasındaki ilişki

Çalışmamızda elde edilen bulgular ile diğer ülkelerden elde edilen bulguların genel olarak örtüştüğü görülmektedir. Japonya'da Japon nanesinden ( $M$. arvensis var. piperascens) alınan $P$. menthae izolatı için optimum sıcaklık $18{ }^{\circ} \mathrm{C}$, maksimum sıcaklık ise $30{ }^{\circ} \mathrm{C}$ olarak bulunmuştur (Ikata, 1929). 1945 yılında ABD'de yapılan bir çalışmada $P$. menthae ürediosporlarının $9-27^{\circ} \mathrm{C}$ arasında çimlendiği ve $18{ }^{\circ} \mathrm{C}^{\prime}$ de en ideal çimlenme ve gelişmeyi gösterdiği bildirilmiştir (Neiderhauser, 1945). ABD'de yapılan bir başka çalışmada farklı nane türlerinden elde edilen izolatların sıcaklık koşullarına farklı tepkiler verdikleri belirtilmiştir. Spearmint mızraklı nane (M. spicata) çeşidinden elde edilen $P$. menthae izolatlarının peppermint hibrit nane çeşitinden (Menthaxpiperita) elde edilen izolatlara göre $28{ }^{\circ} \mathrm{C}$ 'de latent periyodun daha kısa olduğu ve hızlı geliştiği belirlenmiştir. Spearmint izolatlarının ılık havalarda hastalık oluştururken, peppermint izolatlarının serin havaları tercih ettiği bildirilmiştir (Johnson ve Cummings, 2013). Avustralya'da yapılan bir çalışmada ise etmen için optimum sıcaklık $20^{\circ} \mathrm{C}$, maksimum sıcaklık $30^{\circ} \mathrm{C}$ olarak saptanmıştır. Maksimum çimlenmenin $20^{\circ} \mathrm{C}^{\prime}$ de meydana geldiği ve 10,15 ve $25^{\circ} \mathrm{C}$ ile arasında çok az fark olduğu $5^{\circ} \mathrm{C}$ 'de çimlenmenin çok düşük olduğu, $30^{\circ} \mathrm{C}^{\prime}$ de ise 600 sporun sadece üçünün çimlendiğini, $35{ }^{\circ} \mathrm{C}$ 'de hiç çimlenmenin olmadığını bildirmişlerdir (Edwards ve ark., 1998).

\section{SONUÇ}

Bu çalışmada elde edilen bulgular, $P$. menthae'nin serin iklim koşullarını seven bir patojen olduğunu göstermektedir. Daha düşük sıcaklıkların ise enfeksiyon ve sporulasyon süreçlerini yavaşlattığı ve pas fungusunun koşullar uygun hale gelene kadar beklemesine olanak sağladığı söylenebilir. Ayrıca, bu koşullar özellikle serin havanın hakim olduğu ilkbahar ve sonbahar aylarında nanede pas salgınlarının olabileceğini desteklemektedir. Yaz aylarında günlük ortalama sıcaklıkların genellikle 30-40 $\mathrm{C}^{\circ}$ arasında olduğunu göz önünde bulundurursak hastalığın yaz aylarında tehlike arz etmeyeceğini düşünebiliriz. Ancak üretim sırasında nane üretim alanlarında yoğun sulamanın yapılması ve bitkilerin ekiminin sık olması gölgeli, serin, nemli alanlar oluşturacağından bu durumun pas hastalığı için ideal bir ortam olabileceğini unutmamak gerekmektedir.

\section{TEŞEKKÜR}

Bu çalışmada Aydın Adnan Menderes Üniversitesi Tarımsal Biyoteknoloji ve Gıda Güvenliği Uygulama ve Araştırma Merkezi'ne desteklerinden dolayı teşekkür ederim.

\section{KAYNAKLAR}

Anonim (2018) Food and Agriculture Organization of the United Nations. http://www.fao.org/faostat/ . Erişim Tarihi:01.12.2020.

Beresford RM, Mulholland RI (1987) Mint rust on cultivated peppermint in Canterbury: Disease cycle and control by flaming. New Zealand Journal of Experimental Agriculture, 15(2), 229-233.

Edwards J, Parbery DG, Halloran GM, Taylor PA (1998) Assessment of infection and sporulation processes of mint rust on peppermint in controlled conditions. Australian Journal of Agricultural Research, 49: 11251132.

Edwards J (1999) Control of Mint Rust of Peppermint. Epidemiology and Chemical Control, Publication No: 99/122

Edwards J, Halloran GM, Parbery DG, Taylor PA (1999) Physiologic specialisation in Puccinia menthae on peppermint and other hosts in Victoria, Australia. Australasian Plant Pathology, 28: 205-211.

Gobert V, Moja S, Colson M, Taberlet P (2002) Hybridization in the section Mentha (Lamiaceae) inferred from AFLP markers. American Journal of Botany, 89(12), 20172023.

Harvey IC (1979) The impact of rust on peppermint crops in Canterbury 1978/79. Australasian Plant Pathology, 8: 44-45.

Horner CE (1954) Pathogenicity of Verticillium isolates to peppermint. Phytopatology, 44:239-242.

Ikata S (1929). Studien uber die Rostkrankheit japanischer Minze. Review of Applied Mycology, 9, 558.

Johnson DA, Cummings TF (2013) Effects of temperature on rust development on mint infected with strains of Puccinia menthae. Canadian Journal of Plant Pathology, 35.4: 469-475. 
Meyer U, Blum H, Garber U, Hommes M, Pude R, Gabler J (2010) Praxisleitfaden Krankheiten und Schadlinge im Arznei-und Gewürzpflanzenanbau. Spectrum Phytome dizin. Selbst Verlag.183 p.

Neiderhaauser JS (1945) The rust of green house grown mint and its control. Nemers Cornell Agricutural Research Station, 263:30.

Özgüven M, Kırıcı S (1999) Farklı Ekolojilerde Nane Türlerinin Verim ile Uçucu Yağ Oran ve Bileşenlerinin
Araştırılması. T. J. of. Agr. and Forestry, 23(5): 465472.

Tucker AO, Naczi RFC (2007) Mentha: an overview of its classification and relationships in Mint: the genus Mentha, Chapter 1. Ed. Lawrence, B. (Boco Raton, FL.: CRC Press), 1-40. ed. 
